\title{
Value of Percutaneous Transluminal Coronary Angioplasty After Unsuccessful Intravenous Streptokinase Therapy in Acute Myocardial Infarction
}

\author{
ANTHONY Y. FUNG, MD, PETER LAI, MD, ERIC J. TOPOL, MD, \\ ERIC R. BATES, MD, PATRICK D.V. BOURDILLON, MD, JOSEPH A. WALTON, MD, \\ G.B. JOHN MANCINI, MD, THERESA KRYSKI, RN, BERTRAM PITT, MD, \\ and WILLIAM W. O'NEILL, MD
}

The effect of sequential high-dose intravenous streptokinase (SK) (1.5 million units) followed by emergency percutaneous transluminal coronary angioplasty (PTCA) on preserving left ventricular function was assessed prospectively in $\mathbf{3 4}$ patients with acute myocardial infarction (AMI). Intravenous SK therapy was initiated $2.6 \pm 1.3$ hours (mean \pm standard deviation) after the onset of chest pain. Urgent coronary angiography showed persistent total occlusion in 13 patients, significant diameter stenosis (70 to $99 \%$ ) in 18 patients and a widely patent artery (less than $50 \%$ stenosis) in 3 patients. Emergency PTCA was performed in 29 patients 5.0 \pm 2.1 hours after symptom onset. Successful recanalization was achieved in $\mathbf{3 3}$ of the $\mathbf{3 4}$ patients $(97 \%)$ treated with sequential therapy. Repeat contrast ventriculograms recorded 7 to 10 days after intervention in 23 patients showed that the left ventricular ejection fraction increased from $53 \pm$
$12 \%$ to $59 \pm 13 \%$ (area-length method, $p$ $<0.002)$. Regional wall motion of the infarcted segments improved from $-2.7 \pm 1.1$ to $-1.5 \pm 1.7$ $\mathrm{SD} /$ chord (centerline method, $p<0.003$ ). In the subgroup of patients with an occluded artery on initial angiography (group A, $n=10$ ), both global left ventricular ejection fraction $(49 \pm 12 \%$ vs $59 \pm$ $12 \%, p<0.002)$ and regional wall motion $(-3.2 \pm$ 1.0 vs $-1.9 \pm 1.7 \mathrm{SD} /$ chord, $p<0.002$ ) improved significantly. In contrast, no significant improvement was seen in patients with a patent artery on initial angiography $(n=13)$. Thus, sequential intravenous SK and emergency PTCA is efficacious in achieving coronary reperfusion and in improving both global and regional left ventricular function. When thrombolytic therapy fails, successful recanalization can be achieved by emergency PTCA, resulting in significant myocardial salvage.

(Am J Cardiol 1986;58:686-691) hrombolysis with streptokinase (SK) early after the onset of acute myocardial infarction (AMI) can reestablish anterograde coronary blood flow and may salvage myocardium. ${ }^{1}$ However, depending on the route of administration, 20 to $70 \%$ of occluded arteries

From the Division of Cardiology, Dcpartment of Internal Medicine, University of Michigan, Ann Arbor, Michigan. This study was supported in part by a research grant from the USCI Division, Bard Corporation, Billerica, Massachusetts. Manuscript received February 24, 1986; revised manuscript received May 30, 1986, accepted June 3, 1986.

Address for reprints: William W. O'Neill, MD, Cardiology Division, University Hospitals, 1500 East Medical Center Drive, Room B1-F245, Ann Arbor, Michigan 48109. may not be successfully recanalized by thrombolytic agents. ${ }^{2-4}$ Moreover, even if thrombolysis is successful, significant residual stenosis usually remains at the site of initial occlusion. ${ }^{5}$ This may restrict potential increases in coronary blood flow, act as a nidus for rethrombosis and reinfarction, and lead to an unstable clinical course. ${ }^{6-8}$ Recently, emergency percutaneous transluminal coronary angioplasty (PTCA) has been used to recanalize acutely occluded coronary arteries. PTCA causes more complete revascularization, and initial results have been encouraging. ${ }^{9-11} \mathrm{~A}$ major drawback to use of P'I'CA alone as a treatment strategy is the significant interval between onset of chest pain to catheterization and initiation of treatment. Since preservation of myocardium depends in part on the 
speed of reestablishing anterograde coronary blood flow, excessive delay may decrease the likelihood of myocardial salvage. ${ }^{12}$ Sequential therapy using inlravenous SK followed by emergency PTCA is theoretically attractive because this method combines the advantage of early intervention provided by intravenous $\mathrm{SK}^{13}$ with the more "definitive" revascularization provided by PTCA. When thrombolysis by SK is successful, earlier reperfusion is accomplished. If thrombolysis fails, PTCA has the potential to achieve recanalization.

Since no previous clinical trial has used this combined treatment strategy, we prospectively studied 34 patients who received sequential high-dose intravenous SK followed by emergency PTCA for the treatment of AMI. We assessed the safety and morbidity associated with combined therapy and obtained pilot data concerning the impact of such therapy on ventricular function before embarking on a large, multicenter, prospective randomized clinical trial of thrombolysis and PTCA during AMI.

\section{Methods}

Patient selection: Patients with typical chest pain for more than 20 minutes, unrelieved by sublingual nitroglycerin, associated with electrocardiographic evidence of AMI (ST elevation $2 \mathrm{~mm}$ or new pathologic $\mathrm{Q}$ waves in 2 or more leads) were considered eligible for this study. Symptom onset of less than 6 hours was required before initiation of intravenous SK. Exclusion criteria were: cardiogenic shock, prior SK therapy, prior coronary artery bypass surgery, bleeding diathesis, recent surgery, recent cerebrovascular accident, recent cardiopulmonary resuscitation, age older than 75 years, pregnancy or significant hepatic disease. Patients gave informed consent for cardiac catheterization, thrombolysis and PTCA.

Interventional protocol (Fig. 1): After giving informed consent, eligible patients $[97 \%$ ] received premedication intravenously with hydrocortisone, 200 $\mathrm{mg}$. SK, 1.5 million units, was given intravenously over 30 minutes. Meanwhile, arrangements were made to transport the patient to our cardiac catheterization laboratory for emergency angiography.

After placement of vascular sheaths, heparin, 5,000 units, was administered intravenously. Selective coronary angiography was performed using the Judkins technique. This was followed by contrast ventriculography. Patients with at least $70 \%$ stenosis of the infarct-related coronary artery were considered for emergency PTCA. Predefined angiographic exclusion criteria for PTCA were: (1) at least $60 \%$ left main stenosis; (2) "left main equivalent" lesions with at least $70 \%$ diameter stenosis of both the proximal left anterior descending and the proximal left circumflex arteries; (3) inability to identify an infarct-related coronary artery; and (4) distal coronary occlusive lesions judged to be not amenable to PTCA. Angioplasty was performed by the Gruentzig technique ${ }^{14}$ using a steerable guidewire and balloon catheter system (USCI Division, Bard Corp.). Additional heparin, 5,000 units, was given intravenously before PTCA.
After angiography, patients were placed on a medical regimen to prevent rethrombosis, consisting of aspirin, $325 \mathrm{mg} 3$ times per day, dipyridamole, $75 \mathrm{mg} 3$ times per day, and diltiazem, $30 \mathrm{mg} 3$ times per day. Heparin infusion was initiated when the serum fibrinogen level was more than $100 \mathrm{mg} \%$, and therapeutic anticoagulation was maintained until repeat angiography was performed 7 to 10 days later. In addition, lowmolecular-weight dextran, $40 \mathrm{ml} /$ hour, was given intravenously in the first 24 hours.

Analysis of left ventriculograms and coronary angiograms: Outlines of right anterior oblique contrast ventriculograms were traced manually by independent observers blinded to patient's identity, coronary anatomy and sequence of treatment. Ejection fraction was calculated using an area-length method, ${ }^{15}$ Regional wall motion was measured by the computer-assisted centerline chord method described by Bolson et al. ${ }^{16}$ Wall motion abnormality was calculated as the mean motion of chords lying in the most hypokinetic $50 \%$ of the territory of the infarct artery, and expressed in standard deviations per chord (SD/chord). Selective coronary angiography was performed using multiple projections. The projection in which the lesion appeared most severe was chosen for analysis. Percent diameler stenosis was measured using handheld calipers.

Statistical analysis: Valucs reported are mean \pm SD. Paired and nonpaired Student $t$ tests were used where appropriate. Significance was at the $\mathrm{p}<0.05$ level.

\section{Results}

Acute intervention: During a 6-month study period, 115 patients with AMI were referred to our cardiac catheterization laboratory for acute interventional therapy. Of these, 34 patients fulfilled the entry criteria

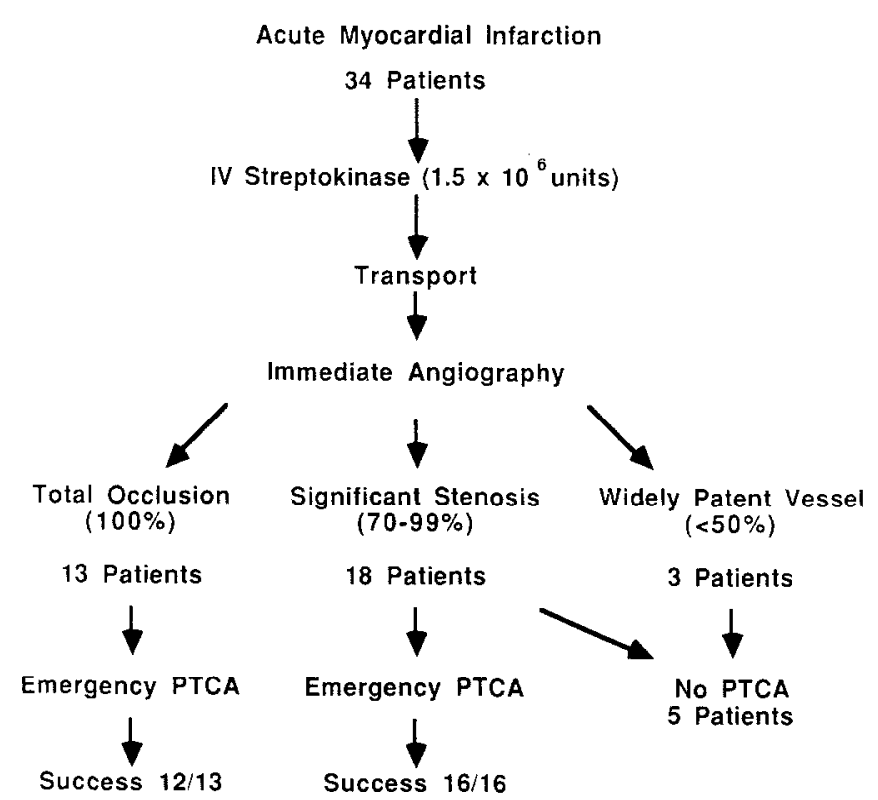

FIGURE 1. Treatment scheme. PTCA = percutaneous transluminal coronary angiography. 
TABLE I Clinical and Angiographic Characteristics

\begin{tabular}{|c|c|c|c|}
\hline & $\begin{array}{c}\text { Group A- } \\
\text { Total } \\
\text { Occlusion }\end{array}$ & $\begin{array}{c}\text { Group B- } \\
70-99 \% \\
\text { Stenosis }\end{array}$ & $\begin{array}{c}\text { Group C- } \\
<50 \% \\
\text { Stenosis }\end{array}$ \\
\hline$n$ & 13 & 18 & 3 \\
\hline Age (yr) & $56 \pm 12$ & $55 \pm 13$ & $50 \pm 6$ \\
\hline Sex ratio (male:female) & $10: 3$ & $16: 2$ & $1: 2$ \\
\hline $\begin{array}{l}\text { Time from symptom onset } \\
\text { to SK (hours) }\end{array}$ & \multicolumn{2}{|c|}{ Time from symptom onset } & $1.8 \pm 0.7$ \\
\hline \multicolumn{4}{|l|}{ Time from symptom onset } \\
\hline \multicolumn{4}{|l|}{ Infarct location } \\
\hline Anterior & 8 & 8 & 2 \\
\hline Inferior & 5 & 10 & 1 \\
\hline \multicolumn{4}{|l|}{ Killip class } \\
\hline 1 & 10 & 17 & 2 \\
\hline il & 1 & 0 & 1 \\
\hline III & 2 & 1 & 0 \\
\hline \multicolumn{4}{|l|}{ Infarct-related artery } \\
\hline LAD & 8 & 8 & 2 \\
\hline $\mathrm{LC}$ & 1 & 1 & 1 \\
\hline Right & 4 & 8 & 0 \\
\hline Unknown & 0 & 1 & 0 \\
\hline \multicolumn{4}{|l|}{ Extent of coronary disease } \\
\hline 0 vessel & 0 & 0 & 2 \\
\hline 1 vessel & 8 & 15 & 1 \\
\hline 2 vessel & 3 & 1 & 0 \\
\hline 3 vessel & 1 & 0 & 0 \\
\hline $\begin{array}{l}\text { Successful PTCA } \\
\text { Severity of stenosis on }\end{array}$ & $12 / 13$ & $16 / 16$ & 一 \\
\hline Initial angiography (\%) & 100 & $88 \pm 9$ & $10 \pm 17$ \\
\hline Post-PTCA stenosis (\%) & $43 \pm 23$ & $34 \pm 14$ & - \\
\hline
\end{tabular}

$L A D=$ left anterior descending coronary artery; $L C=$ left circumflex artery PTCA $=$ percutaneous transluminal coronary angloplasty; $S K=$ streptokinase.

and received intravenous $\mathrm{SK}$ ( 1.5 million units) before arrival in our laboratory. The remaining patients did not receive thrombolytic therapy before transfer either because they failed to meet the entry criteria or because use of intravenous SK had not been approved by the outlying community hospital. They were treated with emergency PTCA if possible. All 34 patients who received intravenous SK had elevated creatine kinase-MB isoenzyme values documenting the presence of AMI. SK therapy was initiated $2.6 \pm 1.3$ hours (range 1 to 6) after the onset of chest pain. Systemic lytic state was achieved in all patients with serum fibrinogen levels of less than $60 \mathrm{mg} \%$ (range $<15$ to 54 $\mathrm{mg} \%$ ) and fibrin split product detectable at more than $1 / 128$ dilution (range $1 / 128$ to $1 / 1024$ ).

At initial angiography, the infarct-related coronary artery was occluded in 13 patients (group A), significantly narrowed (70 to $99 \%$ stenosis) in 18 (group B) and widely patent (less than $50 \%$ stenosis) in 3 (group C). Five of these 34 patients were excluded from PTCA based on predefined criteria mentioned in the Methods section. Three patients had a widely patent vessel (group C), 1 patient had subtotal occlusion of a distal vessel judged to be not amenable to PTCA (group B), and 1 had an inferior infarct with 3-vessel coronary disease in whom an infarct-related vessel could not be identified (group B).

PTCA was attempted in the other 13 group A and 16 group $B$ patients $2.4 \pm 1.3$ hours (range 1 to 6 ) after SK infusion. Mechanical dilatation was successful in 28 patients decreasing the luminal diameter narrowing by at least $20 \%$. The only failure was in a patient with a totally occluded left anterior descending artery in whom PTCA attempt resulted in dissection. That patient's subsequent clinical course was stable. After successful reperfusion with sequential therapy, only 2 patients had residual stenosis of the infarct-related artery of at least $70 \%$. The clinical characteristics and the angiographic data of the 3 groups of patients are summarized in Table I.

Complications: In 6 patients significant hypotension developed during SK infusion. The patients improved after intravenous fluid and slowing of the SK infusion. One patient with anterior infarction became hypotensive after completion of SK therapy and before cardiac catheterization. Angiography showed multivessel disease with complete left anterior descending artery occlusion. That patient died from cardiogenic shock despite recanalization by PTCA. Reperfusion arrhythmia occurred in 9 patients. Sustained ventricular tachycardia or fibrillation occurred in 2 patients, and carioversion was successful in both. Both patients had nonsustained ventricular tachycardia. One patient had transient complete heart block during SK infusion. Bleeding complications occurred in 12 patients, hematoma at the access site in 7 , gastrointestinal bleeding in 3 , hematuria in 1 patient and hemoptysis in 1. Three patients required at least 2 units of blood transfusion, representing significant morbidity. In 1 patient cardiogenic shock developed soon after initial angiography. Total occlusion of the left anterior descending artery was documented on angiography. Recanalization was achieved with PTCA; however, the patient died from pump failure soon after the procedure. Coronary reocclusion was documented in 2 of 26 patients who had repeat cardiac catheterization. Reocclusion was silent in 1 patient and in the other, chest pain developed that was associated with further STsegment elevation 24 hours after successful PTCA. Repeat angiography showed reocclusion and repeat PTCA was successful.

Global ventricular function assessment: Contrast ventriculograms recorded soon after admission (early) were compared with those recorded 7 to 10 days later (late). Of the 13 group A patients with an occluded artery on the initial angiogram, 10 had satisfactory serial ventriculograms for analysis. The late ventriculogram was technically inadequate for analysis in $1 \mathrm{pa}-$ tient, and 2 patients died. Left ventricular ejection fraction improved from $49 \pm 12 \%$ to $59 \pm 12 \%$ ( $n=10$, $\mathrm{p}<0.002$ ) (Fig. 2). In 1 patient reperfusion was not achieved because of coronary dissection during PTCA, and 1 patient had reocclusion. Seven of the remaining 8 patients with persistently recanalized vessels had at least a $5 \%$ increase in ejection fraction. Of the 18 group B patients with a significantly stenosed artery on initial angiography, 13 had satisfactory serial contrast ventriculograms for analysis. Two patients did not undergo PTCA and 2 with an uncomplicated clinical course refused follow-up studies. In 1 patient, the late ventriculogram was technically of poor quality unsuitable for analysis. Left ventricular ejection fraction was $56 \pm 10 \%$ on the initial angiogram and $59 \pm$ $10 \%$ at follow-up ( $\mathrm{n}=13, \mathrm{p}=0.19$ ) (Fig. 2). One patient 
had symptomatic reocclusion. Six of the remaining 12 patients had at least a $5 \%$ increase in ejection fraction. Five of these 6 patients had at least $90 \%$ stenosis of the infarct-related artery on initial angiography. Of the 3 group $\mathrm{C}$ patients with a widely patent artery on the initial angiogram, serial ventriculograms were available only in 1 patient. Ejection fraction improved from $47 \%$ to $54 \%$. The other 2 patients had no discernible coronary lesions on the initial angiogram, and followup studies were not performed.

When all the group $A$ and $B$ patients with satisfactory serial ventriculograms were analyzed $(n=23)$, ejection fraction improved from $53 \pm 12 \%$ to $59 \pm 13 \%$ (p $<0.002$ ). Intergroup comparisons between group $A$ and group $B$ showed a significantly greater increase of mean ejection fraction for group A $[9.9 \pm 6.7 \%$ vs $3.0 \pm$ $7.5 \%, \mathrm{p}<0.04)$. The early ejection fraction in group $A$ tended to be lower, but the difference was not significant $(49 \pm 12 \%$ vs $56 \pm 10 \%, p=0.18$ ). The late ejection fraction of the 2 groups were nearly identical ( $59 \pm$ $12 \%$ vs $59 \pm 10 \%, \mathrm{p}=0.98$ ).

Regional ventricular function assessment: Group A patients achieved significant improvement of regional ventricular function of the infarcted segments $(-3.2 \pm 1.0$ vs $-1.9 \pm 1.7 \mathrm{SD} /$ chord, $\mathrm{p}<0.002, \mathrm{n}=10)$, while group B patients did not $(-2.2 \pm 1.0 \mathrm{vs}-1.2 \pm 1.8$ $\mathrm{SD} /$ chord, $\mathrm{p}=0.06, \mathrm{n}=13$ ). Results are summarized in Figure 3 . Among patients with persistently recanalized vessels, 6 of the 8 patients in group $A$ and 5 of the 12 in group B had improvement of at least $1 \mathrm{SD} /$ chord.

When all group A and group B patients with satisfactory ventriculograms were analyzed, regional ventricular function of the infarcted segments improved from $-2.7 \pm 1.1$ to $-1.5 \pm 1.7 \mathrm{SD} /$ chord $(\mathrm{p}<0.003, \mathrm{n}=$ 23 ), while regional function of the noninfarcted segments did not change $(1.2 \pm 1.5$ vs $1.0 \pm 1.6 \mathrm{SD} /$ chord, $\mathrm{p}=0.55, \mathrm{n}=23$ ). Intergroup comparisons between group $A$ and group B did not yield a significant difference in the degree of regional wall motion improvement $(1.3 \pm 1.2$ vs $1.0 \pm 1.8$, SD/chord, $p=0.67)$. Regional wall motion of the infarcted segments was less hypokinetic in group B patients than in group A patients on early ventriculograms $(-2.2 \pm 1.0 \mathrm{SD} /$ chord for group B vs $-3.2 \pm 1.0 \mathrm{SD} /$ chord for group $\mathrm{A}, \mathrm{p}$

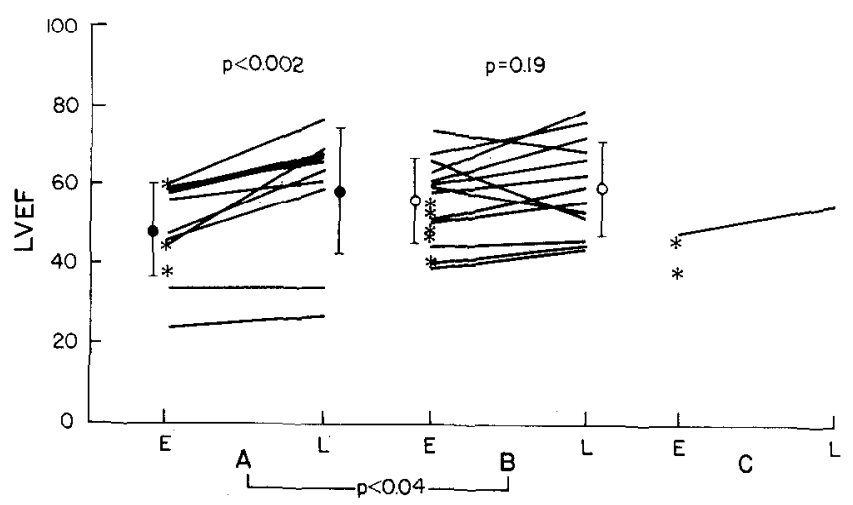

FIGURE 2. Left ventricular ejection fraction (LVEF) on initial angiography (early $[E]$ ) and 10 days after therapy (late [L]) in groups $A$, $B$ and $C$. "Follow-up ventriculogram not available.
$<0.03$, but did not show a significant difference on late ventriculograms $(-1.2 \pm 1.8 \mathrm{SD} /$ chord for group $B$ vs $-1.9 \pm 1.7 \mathrm{SD} /$ chord for group $\mathrm{A}, \mathrm{p}=0.66$ )

\section{Discussion}

Intravenous SK has become an accepted treatment strategy for AMI because of its rapid delivery ${ }^{13,17}$ and efficacy in decreasing mortality. ${ }^{18}$ However, this therapy may have major deficiencies. Irrespective of the route of administration, recanalization may not occur. In addition, thrombolytic therapy is directed only at the thrombotic occlusion that precipitated the acute event, whereas the underlying, often severely stenotic lesion is unaltered. Presence of these residual lesions may have adverse clinical sequelae, including increased incidence of reinfarction or postinfarction angina. ${ }^{19}$

PTCA has been used successfully as the primary method of recanalization in acute coronary occlusion. This is a more definitive form of therapy, permitting dilatation of persisting high-grade residual stenosis and potentially maximizing the degree of coronary reperfusion. ${ }^{9-11}$ However, the time lag required to perform this procedure results in prolongation of ischemia or injury. This problem is most apparent in many community hospitals, where 24-hour angioplasty capability is not available or feasible. Combined intracoronary SK and PTCA has also been uscd successfully in many centers, and was found to be particularly useful when recanalization had failed to occur with intracoronary SK. 9,10,20,21 Such a combined approach, however, required cardiac catheterization before implementation of therapy.

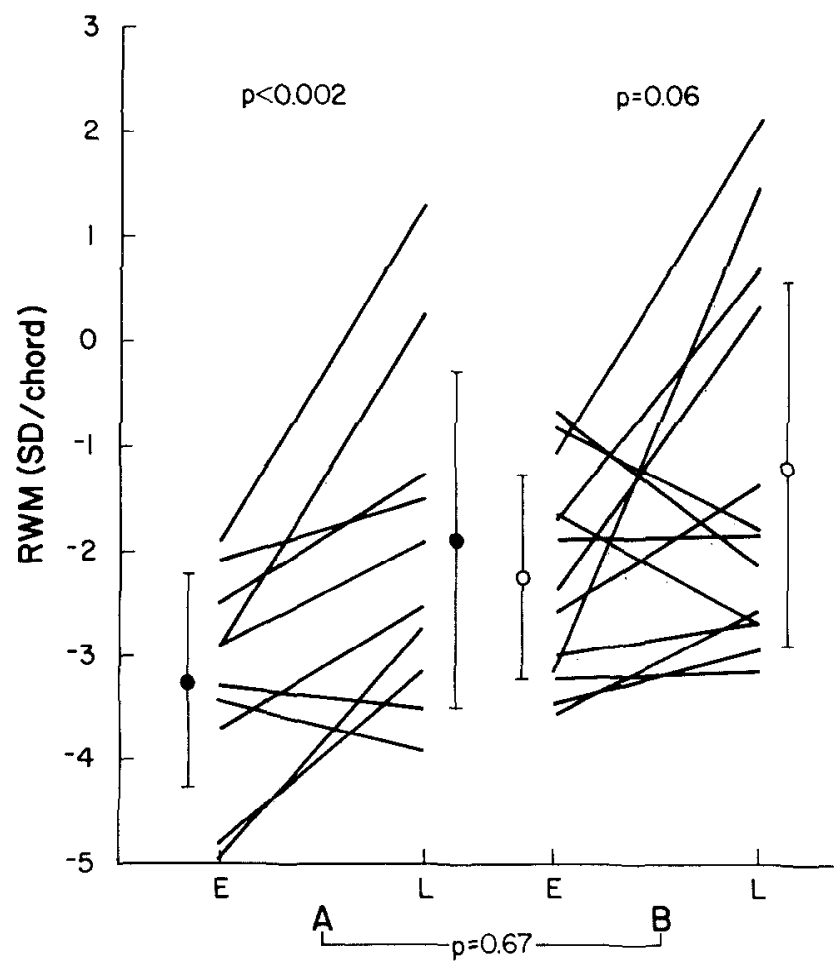

FIGURE 3. Regional wall motion (RWM) of the infarcted segments on initial angiography (early $[E]$ ) and 10 days after therapy (late [L]) in groups $A$ and $B$. 
Thrombolysis: In this study, SK administration preceded emergency PTCA by a mean of 2.5 hours. This time course resulted because the majority of the study patients received SK in the emergency rooms of outlying community hospitals, and there was some inevitable time delay to transport them to the cardiac catheterization laboratory of our hospital. Although angiography was not performed before SK therapy, $62 \%$ of the patients had a patent infarct-related coronary artery on initial angiography. This figure is higher than the $35 \%$ reperfusion rate reported in the Thrombolysis in Myocardial Infarction trial, ${ }^{3}$ lower than the $96 \%$ reported by Ganz et al, ${ }^{17}$ and is similar to the results of Verstraete et al, ${ }^{4}$ Schroder et al ${ }^{22}$ and Anderson et al. ${ }^{23}$ Moreover, this rate is higher than expected in the absence of thrombolytic therapy. ${ }^{24}$ Thus, many of our patients achieved early reperfusion probably as a result of the thrombolytic agent. As expected, most of the recanalized infarct-related coronary arteries had high-grade residual stenosis.

Angioplasty: PTCA was successful in 28 of the 29 patients [97\%] in whom it was attempted. The success rate was high both in patients with occluded arteries and those with significant stenoses. Our results compare favorably with those reported by Papietro et al, ${ }^{21}$ who performed PTCA after intracoronary SK administration. As previous studies have shown, ${ }^{9,10}$ the presence of a systemic lytic state did not appear to adversely affect the performance of PTCA in the present study. Reocclusion occurred in 2 of the 25 patients $(8 \%$ ) who underwent immediate PTCA and repeat angiography despite use of heparin, dextran, aspirin, dipyridamole and a calcium blocker, suggesting that the thrombotic tendency of some vessels is not abolished by sequential therapy and aggressive medical management. Similar results were reported by Erbel et al. ${ }^{25}$

Effect on ventricular function: Both regional and global ventricular function improved significantly after sequential therapy, and this improvement was most apparent in patients who had an occluded infarct-related vessel on the initial angiogram. This benefit may be related to PTCA-induced reperfusion; SK treatment alone had already failed. Previous studies by Rentrop et $\mathrm{al}^{26}$ and Rogers et $\mathrm{al}^{27}$ suggest that patients with incomplete occlusion of the infarct-related coronary artery may have significant improvement of ventricular function after thrombolytic therapy. In the current study, patients who had already achieved recanalization before PTCA showed less hypokinesia of the infarcted segments on baseline ventriculograms $(-2.2 \pm 1.0$ for group B vs $-3.2 \pm 1.0 \mathrm{SD} /$ chord for group A, $\mathrm{p}<0.03$ ), with a trend toward a higher baseline ejection fraction $(56 \pm 10 \%$ for group $B$ vs $49 \pm$ $12 \%$ for group $A, p=0.18$, perhaps reflecting the early beneficial effects of either spontaneous or SK-induced reperfusion. This is consistent with the observation that ejection reaction during the acute phase of infarction is higher in patients with incomplete occlusions that permit rosidual anterograde flow. ${ }^{28}$ After PTCA, further improvement of ventricular function was not shown statistically in this subgroup of patients, although a trend was suggested for global ( $56 \pm 10 \%$ vs
$59 \pm 10 \%, \mathrm{p}=0.19)$ and regional function $(-2.2 \pm 1.0 \mathrm{vs}$ $-1.2 \pm 1.8 \mathrm{SD} /$ chord, $\mathrm{p}=0.06$ ).

Limitations: We attempted to define the feasibility of sequential lytic and mechanical reperfusion; this was not a randomized study. Since a placebo control group is absent, definitive statements concerning changes in ventricular function are not possible. Other studies, ${ }^{29,30}$ however, have shown insignificant improvement in ventricular function after conservative treatment. Persistent complete occlusion on initial angiography may not always indicate thrombolytic failure, as delayed lysis may occur. Whether patients undergoing delayed reperfusion improve ventricular function chronically is unknown. Because of the small sample size, the impact of this therapy on the mortality rate cannot be addressed.

Conclusion: While intravenous SK therapy effectively induces reperfusion in many patients after AMI, complete occlusion or high-grade residual lesions persist in most. Addition of immediate PTCA appears to be an optimal treatment strategy because occluded vessels can be recanalized and residual obstructive lesions can be corrected immediately. Newer thrombolytic agents, such as tissue plasminogen activator, may be more effective than SK in inducing reperfusion. Future randomized trials are required to determine if immediate PTCA will show added benefits when these newer agents are used. However, it is clear that intravenous SK therapy alone does not achieve optimal or maximal coronary recanalization. Sequential intravenous SK followed by immediate PTCA in this study achieved reperfusion with less than $70 \%$ residual stenosis in more than $90 \%$ of cases. Furthermore, the reocclusion rate was only $8 \%$. This treatment strategy therefore appears to be effective and overcomes some of the drawbacks of intravenous thrombolytic agents or PTCA alone, and should be the standard to which other reperfusion strategies are compared.

\section{References}

1. Laffel GL, Braunwald. Thrombolytic therapy: a new strategy for the treatment of acute myocardial infarction (first of 2 parts). $N$ Engl I Med 1984;311:710-717

2. Rentrop KP. Thrombolytic therapy in patients with acute myocardial infarction. Circulation 1985;71:627-632.

3. TIMI Study Group. The Thrombolysis in Myocardial Infarction (TIMI) trial: phase I findings. $N$ Engl I Med 1985;312:932-936.

4. Verstraete M, Bory M, Collen D, Erbel R, Lennane RJ, Mathey D, Michels HR, Schartl M, Uebis E, Bernard R, Brower RW, deBono DP, Huhmann W, Lubsen J, Meyer J, Rutsch W, Schmidt W, von Essen R. Randomized trial of intravenous recombinant tissue-type plasminogen activator versus intravenous streptokinase in acute myocardial infarction. Lancet 1985;1:842-847. 5. Dodge HT, Sheehan FH, Mathey DG, Brown BG, Kennedy JW. Usefulness of coronary artery bypass graft surgery or percutaneous transluminal angioplasty after thrombolytic therapy. Circulation 1985;72:suppl V:V-39-V45 .

6. Harrison DG, Ferguson DW, Collins SM, Skorton DJ, Ericksen EE, Kioschos [M, Marcus ML, White CW. Rethrombosis after reperfusion with streptoklnase in the treatment of acute myocardial infarction. Circulation 1984;69:991999.

7. Gold HK, Leinbach RC, Palacios IF, Yasuda T, Block PC, Buckley MJ, Akins CW, Daggett WM, Austen WG. Goronary reocclusion after selective administration of streptokinase. Circulation 1983:68:suppl I:I-50-I-54.

8. Lee G, Luw RI, Takeda P, Jue P, DeMaria AN, Amsterdam EA, Lui $\mathrm{H}$, Dietrich P, Lee K, Mason DT. Importance of follow-up medical and surgical approaches to prevent reinfarction, reocclusion, and recurrent angina following intracoronary thrombolysis with streptokinase in acute myocardial infarction. Am Heart J 1982;104:921-924. 
9. Meyer I, Merx W, Schmitz H, Erbel R, Kiesslich T, Dorr R, Lambertz H, Betlige C, Krebs W, Bardos P, Minale C, Messmer BJ, Effert S. Percutaneous transluminal coronary angioplasty immediately after intracoronary streptolysis of transmural myocardial infarction. Circulation 1982;66:905-913. 10. Hartzler GO, Rutherfurd BD, McConahay DR, Johmson WL Jr, McCallister BD, Gura GM Jr, Conn RC, Crackett JE. Percutaneous transluminal coronary angioplasty with and without thrombolytic therapy for treatment of acute myocurdial infarction. An Heart / 1983;106:965-973.

11. O'Neill WW, Timmis GC, Bourdillon PD, Lai P, Ganghadarhan V, Walton JA Jr, Ramos RG, Laufer N, Gordon S, Schork MA, Pitt B. A prospective randomized clinical trial of intracoronary streptokinase versus coronary angioplasty therapy of acute myocardial infarction. N Engl I Med 1986;314:812818 .

12. Sheehan FH, Mathey DG, Schofer I, Dodge ITT, Dolson EL. Factors that determine recovery of left ventricular function after thrombolysis in patients with acute myocardial infarction. Circulation 1985;71:1121-1128.

13. Koren G, Weiss AT, I Iasin Y, Appelbaum D, Welber S, Rozenman Y, Lotan C, Mosseri M, Sapoznikov D, Luria MH, Gotsman MS. Prevention of myocardial damage in acute myocardial ischemia by early treatment with intravenous strcptokinase. N Engl I Med 1985;313:1304-1389.

14. Gruntzig AR, Senning A, Siegenthaler WE. Nonoperative dilatation of coronary artery stenosis. N Engl I Med 1979;301:61-68.

15. Dodge HT, Sandler H, Baxlcy $W \Lambda$, Hawley RR. Uscfulness and limitations of radiographic methods for determining left ventricular volume. Am I Cardiol 1966;18:10-24.

16. Bolson EL, Kliman S, Shechan FH, Dodge HT. Left ventricular segmental wall motion: a new method using local direction information. IEEE Comput Cardiol 1980;245-248.

17. Ganz W, Geft I, Shah PK, Low AS, Rodrigucz L, Weiss T, Maddahi J Berman DS, Charuzi Y, Swan HJC. Intravenous streptokinase in evolving acute myocardial infarction. Am I Cardiol 1984;53:1209-1216.

18. Grouppo Italiano Per Lo Studio Della Streptochinasi Noll'Infarcto Miocardio [GGSSI]. Effectiveness of intravenous thrombolytic treatment in acute myocardial infarction. Lancet 1986;1:397-401.

19. Simoons ML, v/d Brand M, de Zwaan C, Verheugt FWA, Remme WI Serruys PW, Bar F, Res ], Krauss XH, Vermeer F, Lubsen I. Improved surviva after early thrombolysis in acute myocardial infarction: a randomized trial by the Interuniversity Cardiology Institute in Netherlands. Lancet 1985;1:578581
20. Gold HK, Cowley MJ, Palacios IF, Vetrovec GW, Akins CW, Block PC, Leinbach RC. Combined intracoronary streptokinase infusion und coronury angioplasty during acute myocardial infarction. Am J Cardiol 1984:53:122C$125 \mathrm{C}$.

21. Papapietro SE, MacLeain WAH, Stanley AWH, Hess RG, Gurley N, Arciniegas IG, Cooper TB. Percutaneous transluminal coronary angioplasty after intracoronary streptokinase in evolving acute myocardial infarction. Am I Curdiul 1985;55:48-53.

22. Schroder R, Biamino G, Leitner ER, Linderer T, Bruggemann T, Heitz I, Vohringer HF, Wegscheider K. Intravenous short term infusion of streptokinose in acute nyocurdial infurction. Circululion 1983;67:536-548.

23. Anderson JL, Marshall HW, Askins JC, Lutz JR, Sorensen SG, Menlove RL, Yanowitz FG, Hagan AD. A randomized trial of intraveonous and intracoronary streptokinase in patients with acute myocardiul infurction. Circulation 1984;70:606-618.

24. DeWood MA, Spores I, Notske R, Mouser LT, Burroughs R, Golden MS Lang IIT. Prevalence of total coronary occlusion during the early hour's of transmural myocardial infarction. N Engl I Med 1980;303:897-902.

25. Erbel R, Pop T, Henkel B, Schreiner G, Rupprecht H, Henrichs K, Meyer ]. Immediate angioplasty after reperfusion in acute myocardial infurction-u prospective controlled randomized trial (abstr). Circulation 1985;72:suppl III:III-223.

26. Rentrop F, Smith H, Painter L, I Iolt J. Changes in left ventricular ejection fraction after intracoronary thrombolytic therapy. Results of the European Society of Cardiology. Circulation 1983;68:suppl I:I-55-I-60.

27. Rogers WJ, Hood WP, Mantle JA, Baxley WA, Kirklin JK, Zorn GL, Nath HP. Returns of left ventricular function after reperfusion in patients with myocardial infarction: importance of subtotal stenosis or intact collaterals. Circulation 1984;69:338-349.

28. Blanke $H$, Cohen $M$, Karsch K, Fagerstrom R, Rentrop P. Prevalence and significance of residual flow to the infarct zone during acute phase of myocardial infarction. IACC 1085;5:827-831.

29. Khaja F, Walton JA, Brymer JF, Lo E, Osterberger L, O'Neill WW, Colfer HT, Weiss R, Lee T, Kurian T, Goldberg AD, Pitt B, Goldstein S. Intracoronary fibrinolytic therapy in acute myocardial infarction. $N$ Engl J Med 1983 308:1306-1311.

30. Kennedy JW, Ritchie JL, Davis KB, Fritz JK. Western Washington randomized trial of intracoronary streptokinase in acute myocardial infarction. $N$ Engl I Med 1983;309:1477-1482. 